\title{
Laparoscopic Puestow: lateral pancreaticojejunostomy
}

\author{
Benjamin R. Biteman ${ }^{1} \cdot$ Jeffrey N. Harr $^{1} \cdot$ Fred Brody $^{1}$
}

Received: 2 December 2015/Accepted: 2 April 2016/Published online: 29 April 2016

(C) Springer Science+Business Media New York 2016

\begin{abstract}
Introduction Chronic pancreatitis is a painful inflammatory disease that leads to progressive and irreversible destruction of pancreatic parenchyma [1]. A lateral pancreaticojejunostomy, also known as the Puestow procedure, is performed for symptomatic chronic pancreatitis associated with a dilated pancreatic duct secondary to calcifications or strictures [2]. An open approach is used traditionally due to the complexity of the case, and there have only been a handful of laparoscopic case reports [3]. This video depicts a laparoscopic lateral pancreaticojejunostomy for chronic pancreatitis.

Methods A 45-year-old gentleman with a 20-year history of chronic alcohol abuse presented with diffuse abdominal pain. His pain was worse postprandially and associated with loose stools. A computed tomography scan revealed multiple calcified deposits within the body and tail of the pancreas, and a dilated pancreatic duct measuring $1.4 \mathrm{~cm}$ with a proximal obstructing calcified stone. A 5-port foregut technique was used, and a $15-\mathrm{cm}$ pancreatic ductotomy was performed with an ultrasonic scalpel. Calcified stones were cleared from the duct, and a roux-en-y pancreaticojejunostomy was performed using a hand-sewn technique.

Results The patient had a relatively uncomplicated hospital course with return of bowel function on postoperative
\end{abstract}

Electronic supplementary material The online version of this article (doi:10.1007/s00464-016-4920-z) contains supplementary material, which is available to authorized users.

Benjamin R. Biteman

brbiteman@gmail.com

1 Department of Surgery, Medical Faculty Associates, The

George Washington University Medical Center, 2150

Pennsylvania Ave NW, 6th Floor, Washington, DC 20073,

USA day 4. His patient-controlled analgesic device was discontinued on post operative day 3 . He was ambulating, tolerating a regular diet and discharged home on postoperative day 5. At 12- and 26-month follow-up, he remains off narcotics, but still requires 1-2 tabs of pancreatic enzyme replacement per meal. Most importantly, he has not had any alcohol for over 2 years.

Conclusion The two primary goals in treating chronic pancreatitis include long-term pain relief and improvements in quality of life [4]. For patients with chronic pancreatitis and a dilated pancreatic duct, a laparoscopic lateral pancreaticojejunostomy may be an effective approach to decrease pain and improve quality of life.

\section{References}

1. Cahen DL, Gouma DJ, Nio Y, Rauws EA, Boermeester MA, Busch OR, Stoker J, Lameris JS, Dijkgraaf MG, Huibregtse K, Bruno MJ (2007) Endoscopic versus surgical drainage of the pancreatic duct in chronic pancreatitis. N Engl J Med 357:676-684

2. Peustow CB, Gillesby WJ (1958) Retrograde surgical drainage of pancreas for chronic relapsing pancreatitis. AMA Arch Surg 76(6):898-907

3. D'Haese JG, Ceyhan GO, Demir IE, Tieftrunk E, Friess H (2014) Treatment options in painful chronic pancreatitis: a systematic review. HBP (Oxford) 16(6):512-521

4. Sukharamwala PB, Patel KD, Teta AF, Parikh S, Ross SB, Carrie E, Rosemurgy AS (2015) Long-term outcomes favor duodenumpreserving pancreatic head resection over pylorus-preserving pancreaticoduodenectomy for chronic pancreatitis: a meta-analysis and systematic review. Am Surg 81(9):909-914 